\title{
Sustainable land use: A farm forester's perspective
}

\author{
BENJAMIN LEE \\ President, Taupo and Districts Branch, New Zealand Farm Forestry \\ bslee@farmside.co.nz
}

\section{Background}

With its first National Annual General Meeting in 1955, The New Zealand Farm Forestry Association was formed by farmers interested in planting trees for a variety of reasons: soil erosion control, shade and shelter for livestock, timber and round wood production for use on farm and logs for sale.

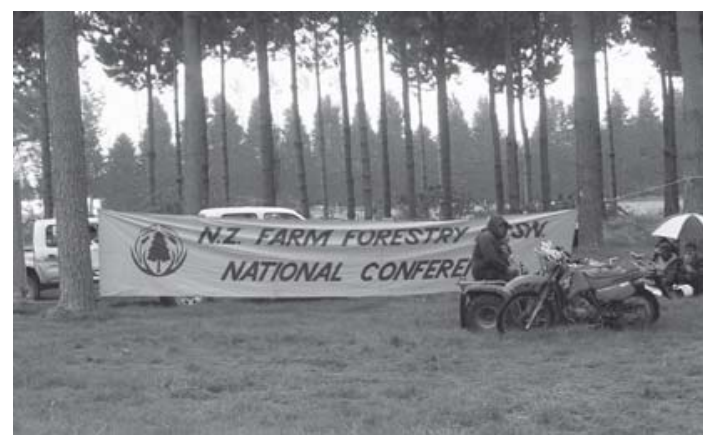

From its inception NZFFA members had access to expertise from the New Zealand Forest Service and Ministry of Forestry through extension officers. Knowledge and expertise was built up within the Association and in the 1990 s membership peaked at 4,500 .

Farm Forestry is defined as the integration of plantation forestry and in some cases indigenous forestry into a farming operation. NZFFA members continue to encourage non members in the farming community to adopt this philosophy. Plantation forestry is a significant land use in New Zealand with plantations covering 1.8 million hectares. However, that area is now shrinking for the first time in the history of New Zealand

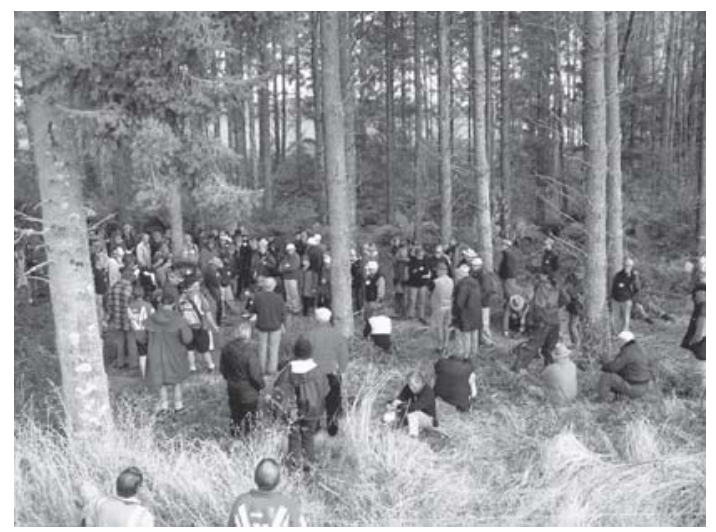

forestry. Plantations are a significant resource on New Zealand farms but area, species and age data are somewhat vague. Currently, because of low log prices, largely due to the high exchange rate, there is a negative spin off relating to new planting. Another issue of concern is that there is a low number of young academics entering into forestry training. Yet we claim that the forest industry is the number three industry in New Zealand behind the Primary Industry and Tourism.

There was renewed interest in the wake of the 1993 log price spike and high levels of planting followed. A significant part of this was on farms, although it could be argued that this planting boom did not result in optimal land use decisions with little of the land that needs forest cover actually being planted and large areas of class $\mathrm{V}$ land or better being planted. Over the last five years, new planting has dropped to close to zero and deforestation has increased. While this might be blamed on declining log prices, the 'green solution calculator' comprising software designed by Ensis that compares forestry and pastoral farming returns, indicates that on land carrying less than, say, $5 \mathrm{su} / \mathrm{ha}$, radiata pine is generally more profitable. In addition to that, returns for Douglas fir and good quality cypress logs have been very good.

\section{Advantages of forestry compared to pastoral farming}

Some of the advantages are environmental in nature though some major economic consequences flow on from a number of these effects (Table 1). Forestry offers the following environmental advantages for pastoral farming:

- Reduced soil erosion.

- Improved water quality in streams, rivers and lakes with reductions in nutrient run-off, sediments, coliforms and lower water temperatures.

- Carbon sequestration - lack of science.

- Increased indigenous biodiversity.

- Improved animal welfare with shade and shelter.

- Amenity gains.

\section{Choosing the site}

Given that forest plantings are well sited -i.e. on lower classes of land, it should be recognised that forestry is not competing with pastoral farming on the more fertile and possibly flatter land. As the 'green solution 
Table 1 Contribution of forestry to farm income

\begin{tabular}{|c|c|c|c|c|c|c|c|}
\hline Year & $\begin{array}{l}\text { Farm } \\
\text { revenue }^{1} \\
\$ K\end{array}$ & $\begin{array}{l}\text { Forestry } \\
\text { revenue } \\
\quad \$ K\end{array}$ & $\begin{array}{c}\text { Forestry } \\
\text { as \% of } \\
\text { GFI }\end{array}$ & $\begin{array}{c}\text { Area } \\
\text { clear felled } \\
\text { (ha) }\end{array}$ & $\begin{array}{l}\text { Age of } \\
\text { clear fell } \\
\text { (yrs) }\end{array}$ & $\begin{array}{c}\text { Area } \\
\text { thinned } \\
\text { (ha) }\end{array}$ & $\begin{array}{l}\text { Stock capacity } \\
\text { of clear fell }{ }^{5} \\
\text { (Total s.u.) }\end{array}$ \\
\hline $89 / 90$ & 95.0 & 25.0 & 26 & 1.5 & 28 & 5 & 7 \\
\hline $90 / 91$ & 139.0 & 53.0 & 38 & 5.0 & $21 \& 29$ & 5 & 25 \\
\hline $91 / 92$ & 117.0 & 31.0 & 26 & 0.8 & 28 & 7 & $4-5$ \\
\hline $92 / 93$ & 140.0 & 43.0 & 31 & 0.6 & 28 & 4 & 4 \\
\hline $93 / 94$ & 199.0 & 86.0 & 43 & 1.2 & 31 & 3 & $12-15$ \\
\hline $94 / 95$ & 154.0 & 74.0 & 48 & 1.7 & 28 & 2 & $12-15$ \\
\hline $95 / 96$ & 169.0 & 92.0 & 54 & 2.6 & 29 & 2.5 & 15 \\
\hline $96 / 97$ & 164.5 & 85.5 & 52 & 2.2 & 30 & 3 & 12 \\
\hline 97/98 & 173.5 & 93.5 & 54 & 3.0 & 29 & 2 & 15 \\
\hline 98/99 & 157.5 & 82.0 & 52 & 3.0 & 30 & 2 & $12-15$ \\
\hline $99 / 00$ & 188.0 & 94.0 & 50 & 3.0 & 29 & 5.5 & $15-20$ \\
\hline 00/01 & 185.5 & 71.0 & 38 & 2.0 & $27 \& 28$ & 0 & $8-10$ \\
\hline 01/02 & 148.5 & 20.5 & 14 & SB & $30-40$ & 5 & \\
\hline $02 / 03$ & 169.0 & 77.0 & 46 & 1.5 & $28 \& 39$ & 0 & $10-12$ \\
\hline 03/04 & 127.0 & 33.0 & 26 & 0.6 & 40 & 3 & 7 \\
\hline 04/05 & 147.0 & 46.5 & 32 & 2.0 & $28 \& 48$ & 7 & $15-20$ \\
\hline 05/06 & 144.0 & 37.5 & 26 & 1.0 & 28 & 4 & 5 \\
\hline $06 / 07$ & 173.0 & 88.0 & 51 & 2.5 & $25 \& 28$ & 12 & $12-15$ \\
\hline
\end{tabular}

1 Gross farm revenue at farm gate, GST exclusive.

${ }^{2}$ Gross forestry returns at farm gate, including harvesting and loading costs but excluding cartage. This may be considered to favour forestry, but compare harvesting costs for wool. Clearfell harvesting costs as a percentage of gross returns have varied from around $10 \%$ in mid 1990 s to $30 \%$ in 2007.

${ }^{3}$ Up to 2001, forestry harvesting was almost exclusively radiata pine woodlots, but since 2003 has included C. macrocarpa and eucalypts, some of which were milled on-farm and in some cases used on farm (notably in new cattle yards), or sold as sawn timber. Area felled: $01 / 02$ - shelterbelts only; 02/03 - 1 ha pine, 0.5 ha macrocarpa; $03 / 04-0.6$ ha macrocarpa; 04/05 - some mixed species felled and used on-farm; 06/07 - plus timber belts.

${ }^{4}$ Production thinning including roundwood for posts, and small sawlogs, is a minor contributor to returns, typically $\$ 1,000$ - $\$ 2,000 /$ ha compared to clearfell at $\$ 15-25,000 /$ ha, but costs are very high, up to $80-90 \%$ of gross returns.

${ }^{5}$ Stock carrying capacity of the forested area makes no allowance for grazing of the plantations.

calculator' (Ensis) confirms, forestry is better suited to lower producing land; ie. class 6 and 7 land. The Farm Foresters experience has been that considerable areas can be afforested on hill properties before stock numbers need to be reduced.

a. Start planting lower producing areas which are often erosion prone.

b. Some grazing is available up to mid rotation of a woodlot at around $12-15$ years.

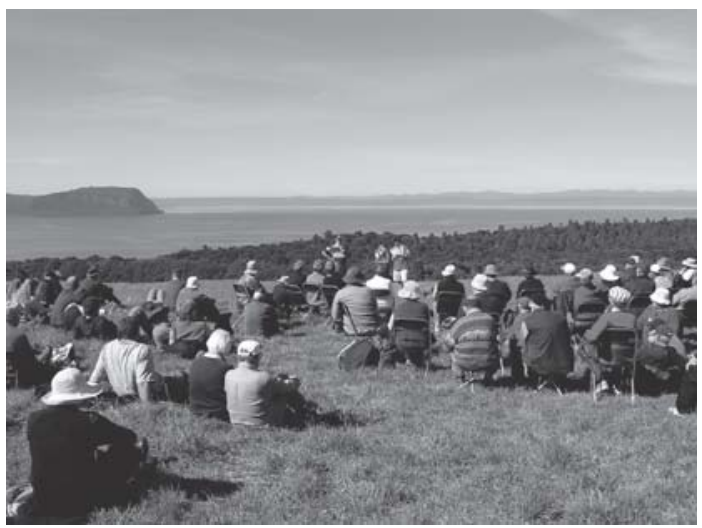

c. Farm input costs can be reduced - eg fertiliser, weed control, stock control is made easier once initial woodlot establishment has been carried out - at a cost of $\$ 4000$ - $\$ 6000$.

d. Small to medium sized forest blocks on farms or $100 \%$ forest blocks have good potential for estate planning, retirement options etc.

\section{Alternate species}

Momentum is gathering with the trialling and researching of alternate species. Within NZFFA there are number of action groups:

- Eucalypts - hardwoods and durable species.

- Cypress - semi durable, low processing costs.

- Redwoods, California Sequoia sempervirens.

- Acacia melanoxylon-Blackwood Tasmania

- Indigenous Forest Group.

Over many years knowledge has been built up around appropriate siting of these different species for climate, soil and forest health issues and silviculture management. Milling and drying are very important the marketing knowledge is being grown.

To this end, along with work from NZFFA members, we are fortunate to have some ongoing research work 
from Ensis/Scion regarding tree breeding, forest health and biosecurity.

\section{Locally produced and marketed product}

New Zealand, because of its large Pinus radiata estate of 1.8 million hectares, produces most of the country's wood fibre products. But for the year ended 30 June 2007 we imported a total of $59000 \mathrm{~m}^{3}$ of solid wood (both soft and hard woods), to the value of $\$ 68$ million. A lot of this could have been grown in New Zealand ${ }^{1}$. 